\title{
MEMORIA E IDENTIDAD EN MISSING (UNA INVESTIGACIÓN)
}

\author{
Angélica Tornero Salinas* \\ Universidad Autónoma del Estado de Morelos \\ angelica.tornero.s@gmail.com
}

Fecha de recepción: agosto de 2017 Fecha de aceptación: diciembre de 2017

Resumen: El objetivo en este artículo es explorar en Missing (una investigación) (2009), de Alberto Fuguet, las formas de la memoria y de la identidad en relación con el principal tópico del libro, la desaparición. Para alcanzar este objetivo, en un primer inciso desarrollamos un marco referencial en el que se exploran las aproximaciones al tiempo, la memoria y la identidad

Angélica Tornero Salinas es profesora-investigadora en la Universidad Autónoma del Estado de Morelos y es profesora de tiempo parcial en la Universidad Nacional Autónoma de México. Tiene el grado de Doctorado en Letras Iberoamericanas y el de Doctorado en Filosofía. Entre sus publicaciones más recientes ha coordinado Yo-grafías. Autoficción en la literatura y el cine hispánicos (Madrid: Síntesis/ULA, 2017); de su autoría propia ha aparecido Identidades, literaturas, reconstrucciones: politicas y poéticas (México: Juan Pablos/ UAEM, 2015). También ha publicado capítulos de libros entre los que destaca "Singularidades e intermediaciones en la constitución de sujeto transmoderno latinoamericano", recogido en El autor a escena, de Ana Casas (coord.) (Madrid: Iberoamericana, Vervuert, 2017). También escribió el capítulo "Intermedialidades, intermediaciones y configuración de singularidades en novelas hispanoamericanas recientes" compilado en Intermedialidades en las artes visuales y la literatura (México: Juan Pablos/UAEM, 2017). Poco antes de ello, colaboró con el capítulo titulado "Roland Barthes por Roland Barthes. Entre la autobiografía y la autoficción”, incluido en Anuario de Letras Modernas (México: Universidad Nacional Autónoma de México, 2016). 
en diversos momentos en el siglo XX, así como algunas consideraciones conceptuales, especialmente del filósofo francés Paul Ricoeur. Enseguida examinamos la manera en que este autor se acercó, en obras anteriores, a tópicos relacionados con el tiempo, la memoria y la identidad, con el fin de ofrecer un marco más amplio de comprensión del lugar que ocupa Missing (una investigación) en relación con esos trabajos. En la última parte analizamos las formas de la memoria y de la identidad en Missing (una investigación). Concluimos que es un texto híbrido que difícilmente puede tipificarse y que, más allá de esto, no tiene sentido intentar hacerlo. Sus aciertos consisten en emplear un número importante de recursos literarios con los que se emborronan la ficción y la realidad, lo público y lo privado. Uno de los recursos más destacados es el uso del punto de vista, el cual es plural. De manera correlativa a esta pluralidad, pueden diferenciarse formas de la memoria e identidad.

Palabras Clave: Memoria, identidad, ficción, literatura latinoamericana.

\section{MEMORY AND IDENTITY IN MISSING (UNA INVESTIGACIÓN)}

ABSTRACT: The aim in this article is to explore in Alberto Fuguet's book, Missing (una investigación) (2009), the shapes of memory and identity concerning the main topic of this book: a lost person. To fulfill this aim, firstly, we built up a frame of reference in order to explore some approaches to time, memory, and identity at various moments in the 20th century, as well as some conceptual considerations, especially of Frech philosopher Paul Ricoeur. Then we examin the ways in which this author moved towards topics related to time, memory and identity, in earlier works, in order to provide a broader understanding of the place Missing (una investigacion) ocuppies regarding those woks. In the last part of this article, we examin the shapes of memory and identity in Missing 
(una investigación). We conclude that this hybrid text can hardly be defined and that, beyond this, there is no sense in trying to do it. Its strength consist of the numerous literary resources used to erase differences between reality and fiction, and the private and the public spheres. One of this resources is the point of view, that is plural. Correlatively to this plurality of the point of view, shapes of memory can be differentiated as well as shapes of identity.

KEYwORDs: Memory, identity, fiction, Latinamerican literature.

\section{Introducción}

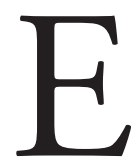

n la década de los ochenta, diversas instituciones (ministerios, medios de comunicación) acaparan el pasado, motivadas por el debate sobre el Holocausto. Se realizan conmemoraciones de todo tipo, se recogen testimonios y se producen series televisivas. Al respecto, Andreas Huyssen (2002) y Tzvetan Todorov (2000) señalan que este fenómeno puede deberse a la necesidad de recuperar los elementos de identidad local amenazados por la globalización del mundo. Una razón más, que espeta Todorov (2000), es el combate por la memoria y la justicia, lo cual puede hacernos olvidar nuestra responsabilidad por el presente, $y$ una tercera es convencer a los demás que el grupo al que pertenecemos fue víctima de la injusticia, lo que abre en el presente una "línea de crédito inagotable" (p. 54).

Sea como sea, estos movimientos han dado lugar a "la cultura de la memoria”, que se ha extendido por diversos países en América Latina. Algunos escritores y artistas, que se han adherido a esta preocupación, abordan aspectos relacionados con la violencia que han enfrentado sus países. Hay un interés por evidenciar las atrocidades cometidas en las dictaduras o regímenes totalitarios en el siglo XX. 
En este contexto general de interés por el pasado, hay autores que han optado por narrar también experiencias más personales, relacionadas con sus vidas familiares, sin que estos escritos puedan considerarse especialmente autobiográficos, sino más bien variaciones en torno al yo autoral. Ejemplo de ello son Educar a los topos (2006), del escritor mexicano Guillermo Fadanelli; Canción de tumba (2011), del también mexicano Julián Herbert o Sangre en el ojo (2012) de la chilena Lina Meruane. La literatura que aquí exploramos del escritor nacido en Santiago de Chile, Alberto Fuguet, se inserta en la preocupación por la recuperación, debido a que constantemente abreva del pasado. En principio es su propio pasado lo que le interesa.

En las obras de Fuguet, los hechos ocurridos a los otros que lo rodean o el pasado histórico está en función de la rememoración de las situaciones en las que ha estado implicado y que lo conducen al reconocimiento de sí mismo. Missing (una investigación) (2009) no es la excepción. En este libro la memoria y la identidad ocupan un lugar sobresaliente. El objetivo en este artículo es explorar cómo estos dos asuntos son configurados para abordar el tópico principal: la desaparición o el estar perdido.

\section{Tiempo, Memoria e Identidad: Consideraciones Conceptuales}

En la segunda consideración intempestiva, publicada originalmente en 1874, Nietzsche (1959) interpreta como un mal, "como una enfermedad y un vicio" (p. 88), el orgullo que la sociedad de su época experimenta por "su cultura histórica" (p. 88). Para el filósofo, las maneras de estudiar la historia resultan destructoras, debido a que depauperan la vida (p. 87). Dos son los blancos de las críticas de Nietzsche, por una parte, el historicismo ${ }^{1}$,

1 El historicismo puede entenderse de tres maneras: primero, como estudios que 
expuesto principalmente en la propuesta de Leopold von Ranke, cuya base es recuperar documentos, y por otra, la perspectiva de Hegel sobre la Historia ${ }^{2}$. Para Nietzsche, los sistemas teleológicos de la filosofía también significaban un intento de dominación de la historia (Frey, 2015).

Estas críticas a la filosofía de la historia y al historicismo no se orientaban únicamente a los usos que de estos enfoques hacía la academia, sino principalmente a las repercusiones que la politización del pasado podía tener en el imaginario popular de cara a la construcción de la identidad nacional alemana. Nietzsche identifica tres usos de la historia: la "historia monumental", la "historia anticuaria" y la "historia crítica". Las dos primeras se erigían para servirse de la vida del pasado y no para servir a la vida del presente. La "historia monumental" contempla el pasado "como si fuera imitable y posible una segunda vez" (p. 102) y la "historia anticuaria", "no tiende más que a conservar la vida, y no a engendrar otra nueva” (p. 108). Pero tampoco la "historia crítica" que estaría más próxima a lo que el autor de Genealogía de la moral querría, sería suficiente si tuviera como único fin "el aumento de los conocimientos" y no el de servir a la vida (p. 110).

Nietzsche no criticaba al pasado, sino la tendencia a hipostasiar a la vida del ser humano al pasado historiado que resultaba del imperativo del recuerdo

aceptan la objetividad de los hechos y de las fuentes y, por tanto, como estudios profesionales de alta especialidad; segundo, como aproximación a los estudios históricos que hace énfasis en el carácter individual y contingente de las épocas y eventos históricos; $y$, tercero, simplemente como historizar virtualmente cada aspecto de la vida cultural (Emden, 2008, p. 139). La traducción es nuestra.

2 De acuerdo con Kittsteinger en la "Segunda intempestiva" no solamente hay una crítica al historicismo: "Aquí radica también el meollo de la doble estrategia que se persigue en este escrito: en el plano obvio se orienta contra el historicismo pero, en el trasfondo, ante todo contra la filosofía de la Historia" (como se citó en Frey, 2015, p. 283). 
que propendía en la época. Por eso, promueve el olvido productivo, aquel que permite vivir: “(...) es absolutamente imposible vivir sin olvidar” (p. 91). El filósofo señala que es posible vivir sin recuerdos y "hasta vivir feliz" (p. 91).

Unos años antes, Baudelaire (2014) bautizaba como "modernidad" a una aproximación artística que consistía en atrapar "lo transitorio, lo fugaz, lo contingente, la mitad del arte cuya otra mitad es lo eterno e inmutable" (p. 22). El poeta critica aquellos acercamientos que expresan el presente a partir de abstracciones derivadas del estudio del arte del pasado. Ser pintor de la vida moderna - y artista, en general — consiste, para el autor de Las flores del mal, en atrapar la belleza pasajera, fugaz, de la vida presente (2014).

En las reflexiones de Baudelaire y Nietzsche subyace un pensamiento transformador del tiempo que abandona el estudio o la apreciación del pasado como aquello que debe imitarse a partir de la abstracción de sus esquemas para dar consistencia al presente y, más tarde, con los movimientos de vanguardia, al futuro. A finales del silgo XIX, los narradores, es patente en Francia, eligieron el realismo para representar el presente, utilizando la simbólica social convencional; es decir, no exploraban formalmente el lenguaje, sino que se utilizaban las formas simbólicas conocidas y familiares, justo lo que criticarían las vanguardias. Estos movimientos dan paso al pensamiento transformador del tiempo entendido no ya en términos de "pretéritos presentes", sino de "futuros presentes" (Huyssen, 2002). En ese momento, los países de occidente tenían la voluntad de olvidar el pasado para que el presente estuviera en condiciones de contener el futuro. El mundo "nuevo" ya no se representa, sino que se crea con el lenguaje.

Nietzsche (1959) pensaba que la historia no permitía engendrar nueva vida, que el pasado podía convertirse en sepulturero del presente ( $p$. 95). La primacía de la tradición para comprender la vida del presente impedía 
imaginar, desde el propio presente, un futuro diferente y novedoso. A partir de estas reflexiones, no solo formalmente, sino también temáticamente, proliferó en la literatura la preocupación sobre la racionalidad, el tiempo, la memoria, la identidad, entre otros tópicos.

Un ejemplo paradigmático de la preocupación por estos asuntos es la obra de Marcel Proust, En busca del tiempo perdido. En la obra de Proust, la memoria afectiva o involuntaria, contrario a lo que hace la memoria voluntaria, más racional, conecta con la vida pasada al recordar las sensaciones resultantes de la percepción sensorial — no del conocimiento científico-, pero aquellas experiencias del pasado no pueden recuperarse en el presente transhistóricamente. El yo del presente no puede recuperar absolutamente al yo del pasado, porque no puede reproducir la percepción sensorial del momento y los sentimientos provocados por aquellas experiencias. Por ese motivo, habrá una distancia entre un yo y otro. Sin embargo, esto no impide que el tiempo pueda ser "recobrado"; la pluralidad de yoes se recupera y adquiere sentido a través de la narración literaria (Souroujon, 2011).

Con los movimientos de contracultura, de los primeros años de la década de los sesenta en Estados Unidos, puedehablarse de "futuros presentes" (Huyssen, 2002), en sentido semejante al que le dieron a esta relación del tiempo las vanguardias europeas. El propósito de estos movimientos hippies era cambiar el mundo con experiencias como las producidas por las drogas, que expandían la conciencia. Es decir, teóricamente, su perspectiva consistía en sentar las bases para la construcción de un mundo mejor en el que reinaran la paz y el amor. Paradójicamente, esta aproximación implicaba acentuar la idea del presente perpetuo, debido a que las experiencias con el rock, las drogas y el sexo extremo involucraban una temporalidad que, de alguna manera, prescindía del pasado y no consideraba como opción la proyección racional hacia el futuro. 
El arte, incluida la literatura, recurrían a esta configuración espontánea y azarosa, como ocurría con el jazz y después el rock, lo que implicó una concepción distinta del tiempo y de la identidad. Aun cuando las novelas escritas por jóvenes narran sus propias experiencias en primera persona, no puede hablarse de autobiografía, al menos como se entendió a partir de Las confesiones de Rousseau. Es también difícil sostener, como han querido algunos críticos, que en esta literatura no hay distancia entre el yo y la escritura, y que tampoco hay monólogo interior o flujo de conciencia, sino lenguaje proveniente de la espontaneidad adolescente (Glantz, 1994, pp. 215-216). Los efectos de las drogas — del rock e incluso el sexo extremo— en estos jóvenes evidentemente los disponen a escribir de manera diferente de como lo haría alguien que no ha alterado su estado de conciencia por esto medios, por lo que la relación entre el yo y la escritura es necesariamente distinta: crea sus propias formas.

En casos como los señalados, la memoria no puede comprenderse como voluntaria y quizá tampoco como afectiva, sino, como quería Nietzsche, aquí tiene que hablarse de olvido para vivir "en" presente. สิ En este sentido, la idea de identidad entendida de manera sustancialista queda descartada. La identidad está constituida, en todo caso, a partir de las acciones que los jóvenes realizan a cada momento, mediando entre los momentos la diferencia.

En la década de los años setenta cada vez resultó más complicado comprender, a partir de las dicotomías que explicaban el mundo todavía durante el capitalismo industrial, un contexto en el que prácticamente toda la cultura, que había invadido a la cotidianidad de las sociedades (Bell, 1977), se convertía en producto de consumo. Las posturas iconoclastas del pop, del rock, y el punk fueron incorporadas a la circulación comercial por lo que perdieron su carácter vanguardista y "quedaron vacías" (Huyssen, 1988, p. 211). En esta década, la conciencia transformadora del tiempo que había 
sedimentado en los "modernos" y en las dos vanguardias, la histórica y la estadounidense, daba un giro espectacular, ahora, hacia el pasado.

Fredric Jameson había anotado ya que uno de los mensajes esenciales del arte de los años setenta implicaría el "necesario fracaso del arte y la estética, el fracaso de lo nuevo, el encarcelamiento en el pasado" (1988, p. 172). Jameson se pregunta si esta tendencia nostálgica es síntoma de la incapacidad de concentrarnos en nuestro propio presente, como si nos hubiésemos vuelto incapaces de conseguir representaciones estéticas de nuestra propia experiencia actual (Jameson, 1988). Esto último quizá sea así. Sin embargo, ir al pasado no necesariamente ha implicado la reclusión de nuestro sentido actual en otro tiempo. Recursos utilizados en la literatura, como la intertextualidad, en el sentido que le da Genette (1989), o el dialogismo bajtiniano y la polifonía (Bajtín, 2004) han resultado ser aproximaciones críticas que de alguna manera deconstruyen los metarrelatos - y conceptos- de la estética y los constructos que dieron solidez a la modernidad, como la idea de sujeto de conocimiento y la de identidad.

La literatura de Alberto Fuguet se inserta en este contexto general de recuperación, debido a que constantemente abreva del pasado. En los siguientes incisos, exploraremos la aproximación de este escritor al pasado. El punto de partida de las reflexiones será la teoría del filósofo Paul Ricoeur sobre la memoria y la identidad, de la cual expondremos, a continuación, algunos aspectos principales.

En sus estudios sobre la voluntad, el filósofo francés afirmó: "El sujeto $(. .$.$) no se conoce a sí mismo directamente, sino solo a través de los$ signos depositados en su memoria y en su imaginario por las grandes culturas" (Ricoeur, 1997, p. 32), con lo cual se distanciaba del sujeto de conocimiento cartesiano y daba cabida a un sujeto hermenéutico. Estas reflexiones lo 
condujeron a pensar que el sujeto de conocimiento es hermenéutico, es decir, interpretativo y que comprende el mundo y a sí mismo, precisamente, interpretando. Lo que este sujeto hermenéutico interpreta es evidentemente el lenguaje, por una parte, los símbolos y metáforas y, por otra, el tiempo narrado, que es la expresión más próxima al tiempo humano (1995).

Estas consideraciones partieron de los estudios literarios y antropológicos que realizó Ricoeur, especialmente de la etnografía. Cuando leemos literatura, sobre todo narrativa, no solo estamos frente a figuras retóricas, sino también encontramos estructuras temporales. Esto último nos permite, como lectores, interpretar a los personajes a partir de sus acciones, evidentemente, realizadas en el tiempo. En el relato el personaje se encuentra inicialmente en una situación A y conforme avanza la trama se modifica a una situación $B$, no solo porque cambió su entorno, sino porque él mismo modificó algún aspecto de su vida o de su comprensión del mundo al cambiar sus circunstancias y el entorno. Los lectores comprendemos e interpretamos lo que les ocurrió a los personajes porque la narración da సิ cuenta del antes y el después (que además se expresan con distintos tiempos verbales) del presente de la narración. Al interpretar de esta manera lo que les ocurrió a los personajes estamos comprendiendo más de ellos, es decir, comprendemos más quiénes son, su identidad.

La identidad configurada literariamente es una identidad narrativa, lo que implica que la literatura constituye identidades narrativamente y no de manera sustancialista como se hace a partir de algunas aproximaciones metafísicas. Pero hay algo más. Al interpretar estas identidades expresadas mediante el lenguaje narrativo, de alguna manera, comprendemos más de nosotros mismos. Como los personajes, nosotros, en nuestras vidas, experimentamos constantemente cambios; la literatura nos permite percatarnos de esto. Algo semejante ocurre a los escritores al leer sus libros 
(son los primeros lectores de sus obras). La lectura de sus textos puede contribuir a una mayor comprensión de sí mismos.

En las diferentes corrientes y tradiciones literarias la constitución de la identidad de los personajes se ha resuelto de distintas maneras, sin embargo, en todos los casos se hace con lenguaje. Así, aunque alguna literatura de vanguardia o posvanguardia, incluso aquella llamada posmoderna, nos imponga no la identidad sino su problematización o su borradura, esto también se hace utilizando el lenguaje y, evidentemente, responde a ciertas inquietudes, que pueden advertirse mediante un estudio contextual.

Los estudios sobre la memoria y su relación con la identidad son vastos. Sin embargo, es imposible aquí reseñar siquiera algunas de las más importantes aproximaciones que dan cuenta de esto. Nos limitaremos, entonces, a considerar un aspecto de la propuesta de Paul Ricoeur, que parece pertinente para este estudio.

El filósofo propone tres sujetos de atribución del recuerdo: el yo, los colectivos y los allegados. Retoma, de ese modo, la aproximaciones fenomenológica y sociológica a la memoria para proponer que en la primera hay ya un planteamiento de memoria intersubjetiva que prevé no una memoria individual, solipsista, sino plural, relacionada con el otro y que implica un nosotros, lo cual se hace evidente al narrar los recuerdos. En “mis" relatos de memoria está presente el otro, porque en el pasado hicimos cosas con otros. Esta perspectiva fenomenológica no es desplazada sino completada por la sociológica, que plantea que la memoria está socialmente mediada por los grupos con los que interactuamos (Ricoeur, 2004). Ricoeur sugiere agregar, entre el polo de la memoria individual y la social, la memoria de los allegados. Esta memoria se diferencia de la colectiva porque el colectivo recuerda sucesos que acontecieron a los otros (por ejemplo, la muerte de alguien), con distancia, mientras que los allegados lo hacen 
con más proximidad: pueden dolerse por la muerte de la persona cercana (Ricoeur, 2004, pp. 162-172).

En la literatura es posible encontrar configuraciones —a través del narrador o de los personajes - de la memoria individual (no de manera solipsista, sino en relación con los otros) o de la colectiva (en un sentido más sociológico) y también la memoria de los allegados. La estructura temporal del relato, que resulta en la posibilidad de comprender narrativamente la identidad de un personaje, está en relación directa a la forma que adquiere la memoria. Una memoria afectiva, como es la configurada en En busca del tiempo perdido, constituye no un yo sino yoes, una identidad discontinua. La tensión entre memoria y olvido en las obras literarias tendrá una disposición distinta en la constitución de la identidad; en algunos casos podría plantearse como identidad nómada y en otros, tender a su borradura.

\section{La Memoria de un Trasplantado}

Alberto Fuguet nació en Santiago de Chile en 1964 y pasó su infancia en Estados Unidos, precisamente, en California, estado en el que - con Nueva York - se gestaban los más importantes movimientos de contracultura de las décadas de los cincuenta y sesenta. La familia decidió regresar a Chile en 1975, lo que implicó para el todavía joven un cambio que marcó su vida personal y profesional de manera definitiva, no solo porque dejaba atrás la experiencia de haber vivido en la primera potencia mundial, tras la Segunda Guerra, sino en el país que trazaba las tendencias culturales que darían identidad al grupo social emergente del que pronto formaría parte: el de los jóvenes.

En sus años en Estados Unidos, Fuguet se describe como un "California boy feliz" al que "le interesaba la playa o la piscina y sin la menor preocupación 
por el mundo intelectual y artístico" (2000). Los ciudadanos no podían vivir al margen de lo que ocurría en el estado más excitante de Estados Unidos, de acuerdo con un artículo del Times, y Fuguet no fue la excepción: "California es una nación en sí misma (...) representa la apacible, impía y gregaria prosecución del placer. Los ciudadanos de la tierra del loto parecen estar siempre recostados junto a piscinas, viendo al sol, paseando por las sierras, retozando desnudos en las playas, más hermosas cada año (...) (Bell, 1977, p. 77). En aquel país experimentó no solo la cultura de masas, sino también —aunque quizá solo de manera indirecta porque todavía era niño - la contracultura, con sus constitutivos, los hippies, las drogas y el rock. El futuro escritor, a su corta edad, leía las revistas Rolling Stones al igual que Mad y, además, tenía en la familia a un practicante de la contracultura, su propio tío Carlos, hermano de su padre y, dicho sea de paso, personaje de Missing (una investigación).

$\mathrm{Al}$ volver a Chile, Alberto Fuguet tuvo que rehacerse en ese (para él) otro país y con otro idioma, y lo hizo sin dejar atrás su pasado: Encino, California, segundo lustro de la década de los sesenta y primero de los setenta. En varias entrevistas, el escritor afirma que, para insertarse en la sociedad chilena, no dejó atrás la identidad con la que se había constituido en California. Su infancia transcurrió en un barrio de clase media, por lo que se mantenía alejado de los guetos de migrantes hispanos, de la cultura latinoamericana y del español. En una entrevista, el escritor señala que quizá conocía el idioma español mucho más de lo que recuerda, sin embargo, insiste en afirmar que su formación fue estadounidense y que su regreso a Chile implicó aprender un idioma y una cultura (Fuguet, 2000).

Fuguet regresó a Chile tras dos ańos del golpe de estado y la instauración del régimen de Augusto Pinochet, por lo que se encontró con una situación perturbadora y, para él, incomprensible en su totalidad. En esos años primeros en Chile, con el fin de ser aceptado en ese "nuevo mundo", 
Fuguet intentó entrar en las "Juventudes comunistas". Sin embargo, comenta en entrevista, se alegra de haber sido rechazado por "gringo" (fue la razón que le espetaron), debido a que se sentía traidor: “(...) yo todavía creía en la onda americana, que Rusia era el país (...) The Evil Empire (...), que Rusia iba a ser el país que nos podía tirar la bomba atómica” (Traviesa, s/f) ${ }^{3}$. Aun cuando muchos aspectos de la vida en Chile eran para él peculiares, el cambio de contexto fue, al menos en dos aspectos, de continuidad: el California boy se topó con un mundo semejante al que vivía, uno en el que prevalecía el liberalismo económico, impuesto por Pinochet desde su llegada, y en el que culturalmente había coincidencias: hippies, drogas y rock, ahora, en la versión chilena. La Generación de la década de los setenta, que precisamente escribía literatura a finales de esa década y en el primer lustro de la de los setenta, abordaba temáticas con las que Fuguet había crecido en California, relacionadas con los intereses de los jóvenes por constituir su identidad.

Además de haberse constituido a partir de estos rasgos de identidad juvenil estadounidense, californiana, de los ańos sesenta, este escritor trasplantado parece haber asimilado profundamente la forma en la que los jóvenes de finales de la década de los setenta y ochenta en Chile se apropiaban de aspectos contraculturales en un país neoliberal con evidente influencia del esteticismo estadounidense. Los jóvenes de los años setenta y ochenta habían ya abandonado el idealismo que había caracterizado a los hippies, con sus consignas de amor y paz, y atribuían sus conductas, mucho más violentas y autodestructivas, a la sensación que experimentaban de haberse quedado sin futuro.

En 1990, Alberto Fuguet publicó el libro de cuentos Sobredosis, cuyo título y portada — la foto de Jack Kerouac en Greenwich Village-

3 La transcripción de la entrevista grabada es nuestra. 
hacen patente su filiación y sus preocupaciones. El escritor utilizaba a uno de los iconos del movimiento de contracultura de la década de los sesenta en Estados Unidos, Kerouac, y además elegía como título un tópico favorito, el uso de drogas. Sin embargo, en los cuentos imprime la experiencia de su propia generación. La droga y el rock no son parte de la propuesta de conformación de una sociedad mejor, en la que prevalecieran el amor y la paz, como pretendían los sesenteros y tampoco es una evocación al sentido que tuvo para la Generación Beat el uso de droga o el andar por los caminos. Aquí, se expresa el individualismo, la fragmentación social, el cinismo, la violencia y la apatía de los jóvenes de la década de los setenta y ochenta, que se han quedado sin motivaciones para enfrentar colectivamente los retos, en busca de condiciones distintas de vida.

Algunos estudiosos y estudiosas de la obra del escritor chileno han advertido el carácter de cronista de Alberto Fuguet (Poblete, 2013) y/o su inquietud por constituir personajes de manera autobiográfica que den voz a sus propias experiencias como joven (Alonso, 2004). Esto último, sobre todo, es un rasgo característico de la aproximación de este escritor a la literatura. En sus libros iniciales habla de sí mismo, de su entorno juvenil y de su época. Así, su literatura se acerca a aquellas propuestas de los años cincuenta y sesenta, en las que los jóvenes escribían desde su experiencia. Sin embargo, hay una diferencia importante. Mientras que Salinger, Kerouac o los mexicanos José Agustín y Parménides García Saldaña, incluso el chileno, Carlos Olivarez, escriben lo que viven prácticamente de manera simultánea, Fuguet hace uso de la memoria, es decir hay distancia temporal entre el momento en que escribe y sobre aquello que escribe, lo cual es mucho más evidente en novelas como Mala onda (1991) o Las películas de mi vida (2003). 
Mala onda (1991), novela escrita cuando Fuguet tenía 27 años, es un Buildungsroman "pervertido" ", cuyo narrador y protagonista es un joven de 17 años. La narración se desarrolla entre el 3 y el 14 de septiembre de 1980, periodo en el que tuvo lugar el plebiscito que apoyó la permanencia de Pinochet en el poder. La historia inicia con la narración del fin de una estancia que Matías Vicuña realizó con los compañeros del colegio en Brasil, durante la cual vivió todo tipo de excesos, drogas, sexo, alcohol, y el regreso a Santiago. Ya en la ciudad, en el marco de la organización del plebiscito, el personaje intenta olvidarse de la insufrible vida al lado de su familia, de sus compañeros de escuela y de la sociedad a la que rechaza.

Para escribir esta novela, Fuguet recurre a la forma literaria conocida y probada, muy exitosa en su momento entre los jóvenes de los años cincuenta y sesenta, incluso en su país, y hace un retake, es decir, una "nueva toma”, la cual, publicada el mismo año en que inicia el periodo democrático en Chile, tiene un éxito comercial inusitado. En una entrevista sobre la novela, Fuguet señala que escribió este libo por la siguiente razón: "Yo quería leer la novela que nunca había leído en el colegio" (como se citó en Alonso, 2004, p. 10). Queda expuesta, así, la intención, señala María Nieves Alonso, de constituir un lector ideal, él mismo, en el pasado y un lector ideal semejante a él para ese presente chileno. Esto conduce a Alonso a una conclusión: "Lo visto y lo vivido, yo y mis circunstancias, biografía y crónica; continuidad y cambios, Mala Onda es, o parece ser, un relato de aprendizaje de la década del 90 en Chile y una historia familiar desarrollada en el año 80" (2004, p. 10).

Esta novela, señala también Alonso, "revela la intención del autor por producir una(s) novelas(s) situadas(s) y articulada(s) por lo

4 Alonso (2004) ha considerado que la novela no responde al Buildungsroman tradicional, sino que es una versión "pervertida". 
retazos de la memoria y la subjetividad (...)" (2004, p. 10). Los recuerdos son del propio Fuguet y el yo que narra es él mismo. Situado en el presente, acude a la memoria para escribir sobre su pasado, cuando era adolescente. Al haber sido escrita años después de ocurridos los hechos, evidentemente se trata de un ejercicio de memoria. Así, la novela acude a dicha categoría para reconstruir un relato que tiene lugar en un espacio y tiempo concretos, con un trasfondo basado en hechos reales y de enorme importancia para el país. Además, apela igualmente a una forma literaria de décadas anteriores, con nostalgia. Hay una clara orientación en esta novela a deponer el futuro por el pasado. Fuguet no parece buscar claves "nuevas" de expresión del presente y de posibilidades de incidir en el futuro, sino que indaga en el pasado, en su pasado. Esta tendencia continúa en algunas de sus obras siguientes.

Sobre Las peliculas de mi vida, el propio Fuguet dijo: "Este es un libro sobe la familia, sobe Chile, la memoria y la historia" (como se citó en Alonso, 2004, p. 10). La novela es una especie de revisión autobiográfica en la que el personaje, Beltrán Soler —alter-ego de Alberto Fuguet-, sismógrafo de profesión, que vivió su infancia en California y siendo adolescente se mudó a Chile, su país natal, toma un vuelo de Santiago de Chile a Tokio para asistir a un evento académico. En el trayecto conoce a una norteamericana que, al contarle anécdotas sobre su vida en Los Ángeles, detona la nostalgia por las tierras en las que creció.

En las páginas iniciales de la novela, Soler dice: "Fue ella la que abrió mi memoria y dejó escapar la viscosa sustancia de la que están hechos los recuerdos" (2003, p. 4). Por cuestiones de programación de vuelos, el personaje tiene que descender en el aeropuerto de Los Ángeles. Se hospeda en un hotel del que no saldrá en varios días, porque se dedicará a escribir sobe su vida personal y familiar, tomando como pretexto las películas que 
vio en su infancia, en California. El personaje dice con una metáfora, como se observa en la cita anterior, que la joven norteamericana "abrió" su memoria, lo que podría interpretarse más como motivación a recordar su infancia. En primer término, el encuentro con la joven le recuerda que tuvo pasado y en segundo, lo mueve a recuperar la experiencia no del pasado como recuento cronológico, sino presuntamente como ejercicio de memoria, como actividad afectiva y vital. En esta novela hay ya claros indicios de deposición del futuro por el pasado: no interesa llegar a Tokio a dictar una conferencia en un evento académico que abone a la trayectoria del profesional. El pasado, recordado con nostalgia, ofrece más elementos de sentido a la vida de Beltrán Soler.

\section{Memoria Personal y Memoria de los Allegados}

Si en Las películas de mi vida, Fuguet muestra de manera palmaria la preocupación por el pasado personal, en Missing (una investigación) ล $(2012)^{5}$ parece no necesitar más pretextos para escribir sobre su vida, sin cortapisas. Fuguet narra un suceso ocurrido en su ámbito familiar, lo cual puede constatarse fácilmente en las numerosas entrevistas y otros escritos en los que ha hablado sobre dicho suceso. Basta con leer algunas publicaciones sobre la vida de este autor o las entrevistas que se le han hecho para de inmediato relacionar la historia narrada en Missing con episodios de su vida. Sin embargo, no es en esta dimensión contextual, de relativamente fácil dilucidación, en donde radica el aporte de este libro. Es más bien el uso consciente de cuantiosos recursos literarios y no literarios, que da como resultado un producto híbrido que es mucho

5 Todas las citas son tomadas de esta edición. 
más que una novela, como dice Vargas Llosa en la cuarta de forros de la edición chilena de la editorial Punto de Lectura (2009), y que resulta interesante analizar desde distintas aristas.

En términos generales, en Missing (una investigación) el narrador emprende una búsqueda planeada para encontrar a su tío Carlos, extraviado años atrás. Esta desaparición, sin explicación aparente, y el poco interés por los miembros de la familia por saber del paradero del tío, son las motivaciones de Alberto para realizar esta pesquisa. Aunque, al final, resulta en algo más que haber encontrado a Carlos: el personaje disipa dudas en relación con su propia identidad, algunos familiares se reconcilian y el tío comprende más las razones por las que se "perdió".

El libro consta de nueve capítulos que, a la vez, se subdividen en apartados. El capítulo primero se titula "Escondido a pleno sol"; debajo de este título aparece un subtítulo con la misma tipografía, pero ya no se utilizan las letras "negritas", sino las normales y la inicial está escrita con minúscula. En este subtítulo se lee: "escribir la historia”. Con este título se indica la intencionalidad del libro: se escribirá la historia de alguien que está "escondido a pleno sol" o desaparecido, precisamente en el sentido que tiene el término en inglés, missing.

En las breves páginas que constituyen este primer capítulo se establecen tres asuntos principales, que contienen algunas de las claves de configuración y, por tanto, de lectura, que deben seguirse para interpretar este libro en el sentido que aquí interesa. Primero, el narrador es escritor. Segundo, el escritor contará la historia de alguien que está desaparecido y que ese alguien, llamado Carlos Fuguet, es su tío (p. 16). Es decir, el narrador, que es también personaje, se apellida Fuguet como el autor, con lo que queda señalada la identidad nominal entre el autor y el personaje. Tercero, el narrador indicará que está escribiendo, por primera vez, "un 
libro para la familia más que acerca de la familia. Un libro pensando en conectar a la familia, más que un libro para poder huir de ella" (p. 18). A juzgar por estos elementos, el libro pudiera "parecer" una autobiografía o un autorretrato familiar, sin embargo, un análisis más detallado evidencia que la dilucidación en torno al carácter del libro no es sencilla, ya que se trata de un híbrido logrado a partir del uso de numerosos recursos literarios.

Estas primeras páginas de Missing están configuradas a partir de la mezcla de asuntos, así como de discursos, lo que provoca indeterminación y ambigüedad. En primer término, hay que señalar la mezcla del discurso ensayístico y el ficcional, que hará que el lector dude sobre el estatuto del libro. Aunque quizá al autor le queda claro que este primer capítulo debe ser leído como un texto reflexivo y, por tanto, de carácter referencial, esto puede no ocurrir con el lector atento, que podrá distinguir dos tipos de discurso.

En los fragmentos de esa primera parte en los que el narrador, a partir de su condición de escritor, establece una tensión entre lo que puede ser para él estar o sentirse perdido, lo que es que alguien cercano esté desaparecido y lo que puede significar para esa persona estar en esa condición, se advierte con claridad el empleo del discurso reflexivo y ensayístico: "No he tenido que perderme porque he podido construirme mi propio planeta y poblarlo con mi gente, decorarlo con mi estética (...). El ser escritor, ser considerado por los demás como uno o incluso como un artista (por pocos, es cierto) ha sido mi bendición” (p. 15).

Sin embargo, en esa primera parte, hay otros fragmentos que son, más bien, reconstrucciones de la memoria y que oscilan entre el discurso referencial y el ficcional: "Me subí a una micro y partí al centro. Al cine. Al cine Metro de la calle Bandera. Vi la cinta. Éramos como cuatro. Siempre veía películas solo. Hide in Plain Sight no era acerca de perderse, pero sí de esconderse, esconderse a plena luz" (p. 17). A pesar de intentar figurar lo que 
ocurrió en el pasado, se advierte la vaguedad de la memoria: "como cuatro". Además, el empleo del adverbio "siempre", puede crear desconfianza en los lectores, en relación con la veracidad de lo que se cuenta. Este tipo de vacilaciones son constantes en este libro.

En segundo término, destaca la problematización de nociones como paratextualidad y metaficción. Podría pensarse inicialmente que este primer capítulo constituye una nota aclaratoria y que, por lo tanto, funciona de manera semejante a un paratexto. Incluso, hacia el final, el autor formaliza, de alguna manera, esta parte: "Ahora todo está avisado, sin máscaras; la idea no es vengarse, ventilar cosas porque sí, andar de rebelde" (p. 19). Se trata de un "aviso", de cierto modo, de una explicación de las razones por las que se escribió este libro. Este aviso, además, apela a un destinatario muy preciso, sus familiares, que forman parte, desde el punto de vista de Ricoeur, de los allegados. Sin embargo, este capítulo es parte del texto, de acuerdo con su ubicación y formalización, por lo que la idea de que sea un paratexto, en la definición de Genette (1989), no puede confirmarse.

Este comentario sobre el texto, que forma parte del texto mismo, podría, entonces, pensarse como metaficción ${ }^{6}$. Sin embargo, hay al menos dos dificultades para que este capítulo pueda considerarse como tal. Primera, en estas páginas el narrador reflexiona sobre su propia condición de perdido y de escritor, lo cual no es un comentario sobre la forma en la que escribió Missing. Por ello, precisamente, se aproxima mucho más al paratexto.

Una segunda dificultad emerge si revisamos el primero de los seis epígrafes ubicados antes de inicio del texto: "Si el lector lo prefiere,

6 De acuerdo con Patricia Waugh (1984), las novelas en las que hay metaficción, de manera autoconsciente y sistemática llaman la atención sobre su condición de artificio, creado para problematizar las relaciones entre ficción y realidad. La traducción es mía. 
puede considerar el libro como obra de ficción. Pero cabe la posibilidad de que un libro de ficción arroje alguna luz sobre las cosas que fueron contadas como hechos", fragmento tomado del prefacio de París era una fiesta de Ernest Hemingway. Con esta frase, Hemingway deja al lector la decisión de leer como ficción o como realidad autobiográfica el texto que le presenta. Esto mismo pretende Fuguet, señalar que el texto es real o referencial y que el lector decidirá la forma en que lo leerá. Así que, si el lector decidiera leer el texto como ficción, quizá podría argumentarse que se trata de un comentario metaficcional ${ }^{7}$ o más bien, como ya señalé, de un paratexto, pero si seguimos el sentido implícito que señala que se trata de un texto real y referencial, entonces, metaficción es un concepto impertinente.

El tercer asunto a destacar de este capítulo primero se relaciona con el tema de la memoria. El narrador considera que su papel como escritor ha sido recordar: "La idea de este libro ha sido recordar. Es lo que me toca, es mi trabajo, la razón quizás por la que vine a la Tierra, mi misión: soy el escritor de la familia (...)” (p. 18). Desde el inicio, la escritura literaria queda definida como aproximación a la memoria afectiva o involuntaria, pero, a la vez, como un ejercicio consciente. Es decir, en este libro se combinan la memoria voluntaria, que organiza de manera más racional el recuerdo y la memoria afectiva, que se advierte, sobre todo, cuando el tío Carlos rememora su pasado, como se verá más adelante.

Aun cuando el narrador comenta, en algún momento en Missing, que se dedica "a contar historias, a vivir a través de otros, de personajes que no existen (...)" (p. 18), coincidimos con María Nieves Alonso (2004) en

7 Como ya señalé, en todo caso, considero muy difícil caracterizar este texto como metaficcional. Podría funcionar más bien como paratexto, aunque tampoco se aviene estrictamente a la noción genettiana. 
que su narrativa trata sobre sí mismo y su entorno, su familia, sus amigos y que de una manera $u$ otra es autorreferencial. Ahora bien, no puede sostenerse fehacientemente que se trata de una autobiografía, debido a que numerosos recursos problematizan las definiciones del género. Me parece que difícilmente puede penarse que el lector hace un pacto de lectura autobiográfico, debido a la inestabilidad del texto, no puede sostenerse que los hechos sean reales y tampoco que sean ficcionales: no hay pureza en ningún sentido.

Uno de los recursos más destacados con los que se logra esta inestabilidad consiste en la configuración del punto de vista en la reconstrucción del pasado, el cual es plural por los siguientes elementos: (a) el punto de vista del narrador-personaje en primera persona, (b) el punto de vista de los allegados, utilizando sobre todo el discurso referido y el directo, (c) en ocasiones, el punto de vista del narrador-personaje desde la infancia y (d) el punto de vista del tío Carlos. La diferencia de puntos de vista más contundente se produce entre el del narrador-personaje y el del tío Carlos. En el capítulo octavo, es Carlos el que narra su vida a Alberto. En este capítulo no hay mayúsculas y está organizado con frases cortas, una debajo de otra. No se trata de un monólogo ni de flujo de conciencia: hay un destinatario del mensaje, Alberto Fuguet, y es clara la intención del tío de comunicarse mediante un discurso narrativo: “(...) fue así: todo pasó el 78/ 1978,/ tu padre aún estaba en chile/ pero ya había llamadas,/ tu padre estaba mal,/ estaba claro que se venía,/ que se volvía,/ que estaba por dejar chile/ y regresar a california (...)” (p. 294).

Aunque la voz de Fuguet, en este capítulo, no aparece en ningún momento, es claro que es el destinatario, y también lo es el lector. El lenguaje utilizado semeja oralidad, así que el lector toma el lugar de aquel a quien se le narra la historia de una vida. Los recuerdos del tío están 
expresados narrativamente, lo que implica que el lector se relaciona con una memoria que recuerda y reproduce acciones. En esta extensa exposición de los recuerdos de Carlos, hay distintas aproximaciones a la memoria. En algunos casos, como señala Ricoeur, se trata de la memoria impedida, aquella memoria herida (2004). Al llegar a vivir a Estados Unidos, el tío tiene que buscar un empleo, debido a la situación precaria por la que atravesaba la familia. De ser estudiante universitario en Chile, a los 19 años tuvo que modificar la comprensión de sí mismo en este país al que había sido trasplantado, sin poder siquiera opinar al respecto: “(...) los primeros meses fueron duros, / a veces pienso en ellos y/ se me aprieta el estómago,/ me llego a sentir mal físicamente/ del puro recuerdo,/ a veces siento que/ vuelvo a tener diecinueve años/ y me da pánico (...)” (p. 190).

Aunque es el tío el que recuerda, no es él quien provocó su propio dolor, sino una circunstancia que podría ser atribuible a otros que decidieron por él. Estos recuerdos dolorosos están en su memoria de una manera en que no lo están en la memoria de los que podrían ser causantes directos ิㅗ de aquella situación. Sí, estos recuerdos recuperados desde la memoria impedida, herida, son personales y son recuerdos que quieren olvidarse porque son dolorosos y, en otro sentido, patológicos. El recuerdo es tan agudo que provoca malestar físico.

Otro momento en que la memoria está próxima a este sentido de memoria impedida se da cuando el tío regala a su padre una máquina de video VHS para que grabar los partidos de fútbol del Mundial, y por respuesta recibe un reclamo. Este es el momento crucial en la historia de Carlos, ya que es cuando decide no volver: “(...) mi padre miró el aparato:/ siempre gastando más de lo que tienes./ callé, no le dije nada, me guardé/ mi respuesta,/ pero las repuestas no se pueden guardar,/ no desaparecen, se sienten en el estómago,/ te aprietan,/ te envenenan por un rato/ y, a veces, 
lo que es peor,/ se te meten a la sangre" (p. 317). Aunque no hay referencias explícitas al acto de recordar, es evidente que la situación lo afectó al punto que guarda en su memoria el dolor frente al rechazo.

También con dolor, pero sobre todo con nostalgia, Carlos recuerda el momento en que se va de luna de miel. Su esposa, estadounidense, y él se conocieron en un cine y se casaron unos días después. Mientras Carlos dormía en el hotel en Nuevo México, Suzette salió a un bar y conoció a un hombre:

(...) steve era vaquero,

vaquero de verdad, y le regaló

marihuana y shots de tequila

y luego llegó al motel

con él y nos presentó y

me pareció todo raro,

yo me molesté

ella me ofreció droga,

le dije que no,

ella me dijo que steve

no tenía donde pasar la noche

porque era de farmington,

podríamos dormir los tres (...)

le dije no, que por qué traía tipos a la pieza,

le pedí a steve que se fuera,

pero steve empezó a besarse con suzette,

o suzette, para sacarme celos, empezó a besarlo a él,

eso me tizó algo,

no sólo me enojó, 
me dolió, me apenó, me desencajó (...). (p. 268)

La única esposa que tuvo Carlos era una mujer liberal, que no aceptaba límites y que, al parecer, hizo sufrir a su marido. Más adelante se lee: “(...) suzette quiso celebrar su cumpleaños en waco/ y se fue en bus./ se quedó dos semanas y me llamó/ una vez, borracha./ volvió con un moretón en la cara/ pero no le dije nada,/ me puse a llorar al verla./ estaba tan enamorado/ o eso creía” (p. 272). A diferencia del recuerdo sobre el desprendimiento de Chile, este recuerdo de la esposa está narrado con distancia. Hay que señalar, aquí, que esta versión de Carlos sobre los hechos difiere de la que tienen los allegados, como se verá más adelante, lo cual refuerza la idea del punto de vista plural y diferente.

En varios fragmentos, los recuerdos de Carlos son menos dolorosos y สิ más reflexivos. Es imposible aquí seguir ejemplificando, debido a limitaciones de espacio. Baste señalar que estos recuerdos abarcan su vida hasta el momento en que se encuentra con Alberto: recuerda las veces que estuvo preso, cuando decidió no volver nunca más a entablar relaciones con la familia, sus distintos trabajos y las otras mujeres que no le significaron nada.

El segundo capítulo, que reproduce una crónica publicada años antes, está narrado en primera persona por Fuguet y da cuenta de las versiones que tienen diversos integrantes de la familia sobre la desaparición de Carlos. La fidelidad de la memoria de los allegados es puesta en duda constantemente por el narrador, lo que provoca que el lector también dude de la veracidad de la información: 
Esa vez que llegó con el equipo de VHS, fue la última que lo vieron. Dicen, porque no está del todo claro, que después hubo una discusión telefónica, creo. (...) Mi padre cogió el teléfono y lo insultó, creo. —Cómo puedes hacerle esto a tu padre que está enfermo - le habría dicho antes de lanzarle una sarta de insultos o algo así- (...). (p. 25)

En esta cita se introduce en dos ocasiones el verbo "creer" y en la última línea la oración disyuntiva, lo que enfatiza la vacilación. Más adelante dice lo siguiente:

Esta conversación telefónica, esta pelea, se me ocurre, fue justamente la gota que rebalsó el vaso (...). Si es verdad que esa llamada sucedió como dicen que sucedió (al menos, sucedió en el mito familiar), entonces ahí, en ese instante, ocurrió algo enfermizo. Pasó algo que no ha debido haber sucedido: un padre se comportó como un hijo. (p. 26)

En este capítulo Fuguet intenta también reconstruir una biografía de su tío, con base en las "historias" familiares, que prácticamente se han convertido en mitos. Tampoco en este caso, Fuguet se fía de la fidelidad de la memoria de sus familiares. Aquí, algunos fragmentos: "Sin duda era el que sacó más premios en el colegio San Pedro Nolasco. Quizá era el más tímido también. Aquí estoy especulando: ¿era el más sensible? (p. 28). "Cuando mi tío cumplió los quince años (creo)" (p. 29). "Dicen que una noche de verano texana fue con un amigo a un bar y vio a una chica rubia bailar arriba de un cubo. Ambos estaban drogados y borrachos: Carlos y Suzette se casaron al día siguiente" (p. 33). "Nadie se acuerda cuando mi tío 
salió de prisión. O quizá sí. Esta parte de la historia es borrosa. (...) Duró — creo- unos dos años vegetando en Orange County. Como era un reo recién liberado, sus oportunidades eran limitadas. No tengo claro en qué se ganó la vida. Un día, quizá aburrido de seguir de alguna manera preso, partió a comprar un auto" (pp. 35-36).

Los recuerdos que tiene Fuguet de su tío tampoco son confiables. En el tiempo efectivo del relato, Fuguet dice gustoso: "El tío que más recuerdo (el mítico y el mejor de todos) era hippie, tacaba bongos, jugaba fútbol, siempre olía a mariguana y llegaba en un Mustang del cual salía música de Jimi Hendrix y Led Zeppelin” (p. 34). Como él mismo lo señala, el recuerdo de este personaje ha quedado casi fijo; ha sido idealizado por algunos allegados. Alberto ha lamentado la desaparición del tío porque para él esta pérdida implicó, de cierto modo, la suya misma. La identificación que tuvo con él, en breves encuentros, fue tan importante que la desaparición del tío era como no contar con una pieza del rompecabezas que le permitiría comprenderse mejor.

En el capítulo cuarto, titulado Missing, se narra la experiencia, en tiempo pasado, del encuentro breve entre Alberto, cuando tenía 17 años, y Carlos Fuguet. La narración, aquí se modifica, lo mismo que el tono. Aparece un narrador en tercera persona, lo que traza una distancia entre el narrador del tiempo presente y este joven, que es él mismo, pero muchos ańos antes. Esto implica una variación más del punto de vista.

Alberto, que había regresado con su madre a Chile, va a visitar a su padre a California. Ahí se encuentra con el tío Carlos. Alberto y Carlos pasan algunas horas juntos, suficiente para que el primero quedara marcado para siempre por la personalidad del tío y durante años pensara que era su doble. El chico, como se refiere el narrador a sí mismo en ese tiempo pasado, considera al tío una especie de héroe al cual admirar y con quien compartir gustos semejantes. 
La configuración de esta voz narrativa en tercera persona confirma la fuerza del recuerdo en Alberto, como si se tratara de la vivencia misma. No narra desde su yo presente, sino desde ese yo pasado, como si el tiempo no hubiera transcurrido y el ejercicio de la memoria pudiera no variar en relación con este suceso. La primera "vivencia" es una conversación, acompañada de unos tragos de alcohol: "Carlos le pregunta [al chico] si fuma mariguana, el chico le dice que prefiere la cocaína. Carlos le dice que le cae bien, que pueden ser amigos. Conversan toda la tarde, hablan de mujeres, de sexo, de pajas, de drogas, de rock, de cine" (p. 84). El tío es para Fuguet, a los 17 años, una especie de héroe. La segunda "vivencia" es semejante: "Las chicas sacan la mariguana. El chico tose y tose pero fuma. Una chica dice que por qué no se van a su casa, que tiene un jacuzzi. El chico considera que Carlos Fuguet es el tipo más cool e intenso del planeta” (p. 85).

La investigación que lleva a cabo Alberto Fuguet sobre el paradero de su tío es también una investigación sobre sí mismo, sobre su identidad. El personaje, a partir de sus recuerdos y de las rememoraciones de los demás, pero sobre todo a partir de la conciencia que en algún momento tiene de su modo ser "un perdido", ha construido una idea en torno a su tío Carlos que le ha permitido mirar con más claridad su propia identidad de persona "perdida". Al reflexionar sobre esto, se da cuenta que hay distintos modos de estar perdido: "Uno se puede perder de muchas maneras estando a plena luz, pero perderse de verdad, quemar las naves, desaparecer, es otra cosa. Es, dentro de todo, un acto de gran valentía o todo lo contrario. No lo sé, no lo he hecho, no lo haré" (p. 16).

Paulatinamente, a Fuguet le queda claro que, en su caso, desaparecer es una postura de autor, del autor real y del ficcional, que responde a su contexto: "Mi tío se perdió, pero se perdió de verdad. Nada de arte, nada de metáforas. Nada de transferencias vicarias" (p. 16). Más adelante, dice: "Algo 
le pasó a Carlos. Antes de que se perdiera, ya estaba perdido. O camino a perderse. ¿Por qué?” (p. 31). Es esta la pregunta a la que intenta responder Missing (una investigación).

Para Carlos la investigación ha sido crucial para la comprensión de sí mismo. La experiencia de narrar su pasado le ha permitido percatarse de la forma en que sus allegados han interpretado su condición de desaparecido y su propia negación del hecho. La reconstrucción del tío Carlos es muy compleja, porque no solo desapareció voluntariamente del horizonte familiar y se quedó sin esos referentes afectivos que le otorgaban existencia, sino porque, antes que eso, había desaparecido de sí mismo, había dejado de comprender quién era, al haber sido trasplantado de un país a otro. De hecho, la emigración a Estados Unidos fue un factor determinante para la desaparición de Carlos. Alberto Fuguet dice al respecto: "Pero el factor América tiene que ver en la ecuación. Mucho, quizá demasiado” (p. 31). Más adelante, el narrador se pregunta: “¿Cómo un chico bueno de Nuuñoa termina con problemas con la ley y, se me ocurre, consigo mismo? No es sencillo rehacerse, menos en otro idioma. Carlos, además, era un adolescente, lo que no facilitó su historia” (p. 31).

Carlos quiso dejar de ser chileno para intentar ser estadounidense plenamente, sin embargo, el propio país lo devora, como él mismo lo menciona: “(...) el país en sí tiene esta cosa,/ esta cosa de que es tan,/ tan grande,/ tan grande y anónimo,/ inabarcable y fragmentado,/ que te puede perder,/ te puedes perder/ y nadie te va a poder encontrar" (p. 163). En Estados Unidos, Carlos se convierte en un ser invisible, no vinculado a nada e ignorante de su propio deseo: "mi historia no tiene que ver con querer irse/ sino con caer,/ con caer aquí,/ en los estados unidos,/ con llegar al otro paraíso y no entenderlo,/ no procesar o procesarlo tarde,/ no haber sido capaz de dominarlo,/ aprovecharme de él,/ sacarle ventaja (...)” (p. 162). 
Hacia el final, el sobrino siente que ha comprendido más sobre sí mismo y su familia en relación con la desaparición de Carlos, por lo que no tiene ya intenciones de publicar el libro; sin embargo, el tío no piensa lo mismo. Pará él es necesario todavía ir más allá:

-Me gustaría que el libro exista antes de que me vaya.

- ¿Qué te vayas a dónde?

-Me gustaría verlo, leerlo, en vida -me dice.

¿Qué me está diciendo...? Prefiero saltarme el tema, no picar. Tampoco creo que sea verdad. ¿O sí? (...)

-Estaba ilusionado.

-Lo sé -le respondo-. Yo también lo estaba. Lo sabes, ¿¿no?

-Lo sé. ¿Es definitivo? (...)

-Yo quería que algún día...

-Sí, sé.

-Que mi historia quedara como una historia. Para que todo haya valido la pena. (...)

-Una vida...

-¿... más rutinaria? (...)

-Una vida que no te pesa. (pp. 383-385)

Para Carlos, la memoria y la oralidad son insuficientes para tener la comprensión cabal de sí mismo. La lectura de Missing le permitiría interpretar-se a partir de la expresión de la temporalidad de su vida para recuperarse y "sentir que todo valió la pena. Que al final al menos tuve un premio” (p. 385). “¿Un premio?”, pregunta el sobrino. “-Me gustaría leer mi vida y ver dónde me perdí./ Primera vez que dice perdido, que dice que se perdió” (p. 385). La investigación permitió al tío asumirse como desparecido y superar esa condición al comprenderla mejor. 


\section{Consideraciones Finales}

Missing (una investigación) es un ejemplo de texto híbrido, que difícilmente puede tipificarse y que, más allá de esto, me parece, no tiene sentido intentar hacerlo. La fortaleza del libro consiste precisamente en haber combinado una serie de recursos literarios y rebasar las tipificaciones. Algunos de los recursos más sobresalientes que hacen de este un híbrido son los siguientes: (a) la identidad nominal entre el autor y el narrador-personaje, (b) cierta forma de aproximación metaficcional y (c) la interdiscursividad; con todos ellos se emborronan la ficción y la realidad, lo público y lo privado.

De cara a los asuntos que aquí se analizaron, la memoria y la historia, uno de los recursos destacados es el manejo del punto de vista. Los dos principales implicados, Alberto y Carlos Fuguet, darán sus puntos de vista de manera directa sobre los hechos en torno a la desaparición de Carlos. Además, a través del narrador, los demás familiares, los allegados, atestarán sobre este suceso.

A cada punto de vista corresponde una forma distinta de la memoria. Alberto recuerda poco, debido a que él era todavía muy joven cuando el tío desapareció. Para recordar al tío, opta por tomar distancia de su presente, narrando el pasado en tercera persona y refiriéndose a él mismo como otro yo, de otro tiempo. Este recurso imprime fuerza a los pocos recuerdos que tiene del tío. La memoria de los allegados, que son los testigos, está mediada por la voz de Alberto, aunque hay un intento de reproducción de los recuerdos tal como los familiares los exponen. En este caso, los recuerdos se formalizan principalmente a partir de la duda.

Los recuerdos de Carlos son narrados sucesivamente mediante distintas formas de la memoria. En algunas situaciones recordadas prevalece la memoria herida, aquella que ha preferido olvidar ante lo doloroso que 
puede resultar el recuerdo; en otras, la memoria voluntaria reconstruye sucesivamente los acontecimientos, con cierta distancia emocional. Para todos estos casos, en Missing (una investigación) queda en evidencia que la memoria no es el ejercicio de un yo solipsista, sino una puesta en escena, en la que están involucrados los otros y en la que las relaciones están mediadas por las acciones.

El ejercicio de recuperación del pasado funciona también como auxiliar en la constitución de la identidad de Alberto y de Carlos. Los resultados de la investigación, haber hallado a Carlos con vida y, más o menos, con salud, disponen a Alberto a continuar con más seguridad, habiendo dispersado sus dudas sobre sí mismo, sus allegados y su tío, al menos en el tema de la desaparición. A diferencia de lo que ocurría en las obras anteriores que mencioné, Sobredosis, Mala onda y Las películas de mi vida, en las que el objetivo de la escritura era la comprensión del personaje de manera más personal, aquí, el interés de Alberto Fuguet (autor o personaje) es comprenderse como parte de un colectivo, el de sus allegados. 


\section{Referencias}

Alonso, M. N. (2004). Alberto Fuguet. Un (in)digno descendiente de una buena tradición. Acta Literaria, (9), 7-31.

Bajtín, M. M. (2004). Problemas de la poética de Dostoievski. Ciudad de México, México: Fondo de Cultura Económica.

Baudelaire, Ch. (2014). El pintor de la vida moderna. La modernidad es lo transitorio, lo fugaz, lo contingente. Ciudad de México, México: Taurus.

Bell, D. (1977). Las contradicciones culturales del capitalismo. Madrid,España: Alianza.

Emden, Ch. J. (2008). The crisis of historical culture. London, United Kingdom: Cambridge University Press.

Frey, H. (2015). Nietzsche: la memoria, la historia: la "Segunda intempestiva" entre la crítica al historicismo y la negación de la filosofía de la historia. Cuicuilco, 22(64), 271-290.

고 Fuguet, A. (1990). Sobredosis. Santiago, Chile: Aguilar Chilena.

Fuguet, A. (1998). Mala Onda. Santiago, Chile: Alfaguara.

Fuguet, A. (2000). Entrevista con Alberto Fuguet. Barcelona Review. Recuperado de http://www.barcelonareview.com/16/s_ent_af.htm Fuguet, A. (2003). Las películas de mi vida. New York, Estados Unidos: Rayo-Harper Collins.

Fuguet, A. (2012). Missing (una investigación). Santiago, Chile: Punto de Lectura.

Fuguet, A. (s/f). Entrevista a Alberto Fuguet. Revista Traviesa. Literatura contemporánea de cerca. Contemporary Fiction Up-Close. Recuperado de http://www.mastraviesa.com/Entrevista-Alberto-Fuguet

Genette, G. (1989). Palimpsestos. La literatura en segundo grado. Madrid, España: Taurus. 
Glantz, M. (1994). Onda y escritura. En Esguince de cintura. Ciudad de México, México: Consejo Nacional para la Cultura y las Artes. Huyssen, A. (1988). Cartografía del posmodernismo. En J, Picó (coord.), Modernidad y posmodernidad. Madrid, España: Alianza Editorial.

Huyssen, A. (2002). Pretéritos presentes, medios, política, amnesia. En En busca del futuro perdido. Cultura y memoria en tiempos de globalización (pp. 13-40). Ciudad de México, México: Fondo de Cultura Económica.

Jameson, F. (1988). Posmodernismo y sociedad de consumo. La posmodernidad (pp. 165-186). Ciudad de México, México: Kairós.

Nietzsche, F. (1959). De la utilidad y de los inconvenientes de los estudios históricos, para la vida. En Obras completas de Federico Nietzsche, II. Consideraciones intempestivas. Buenos Aires, Argentina: Aguilar. Poblete, P. (2013). Alberto Fuguet, cronista. Literatura y lingüistica, (27). Recuperado de http://www.scielo.cl/scielo.php?script=sci_arttext\& pid=S0716-58112013000100006

Ricoeur, P. (1995). Tiempo y narración I. Ciudad de México, México: Siglo XXI. Ricoeur, P. (1997). Autobiografía intelectual. Buenos Aires, Argentina: Nueva Visión.

Ricoeur, P. (2004). La historia, la memoria, el olvido. Ciudad de México, México: Fondo de Cultura Económica.

Souroujon, G. (2011). Reflexiones en torno a la relación entre memoria, identidad e imaginación. Andamios. Revista de Investigación Social, $8(17), 233-257$.

Todorov, T. (2000). Los abusos de la memoria. Barcelona, España: Paidós.

Waugh, P. (1984). Metafiction. The Theory and Practice of Self-Conscious Fiction. New York, Estados Unidos: Methuen. 